\title{
Colon Neuroendocrine Tumor
}

National Cancer Institute

\section{Source}

National Cancer Institute. Colon Neuroendocrine Tumor. NCI Thesaurus. Code C135212.

A well differentiated, low or intermediate grade tumor with neuroendocrine

differentiation that arises from the colon. 